\title{
Inventarisasi Jenis Pohon Buah yang Dibudidayakan di Lembo (Kebun Hutan) di Kecamatan Sambutan, Kota Samarinda
}

\author{
Inventory of Fruit Trees Cultivated in Lembo (Forest Gardens) in Sambutan District \\ Samarinda City \\ Fathiah* \\ Program Studi Pengelolaan Hutan, Politeknik Pertanian Negeri Samarinda, Indonesia \\ *Corresponding Author: fathiah@politanisamarinda.ac.id,
}

\begin{abstract}
ABSTRAK
Masyarakat Sambutan banyak mengelola Lembo (kebun hutan) yang merupakan salah satu pemanfaatan lahan secara tradisional dimana umumnya didominasi oleh vegetasi dan buah-buahan. Penelitian ini bertujuan untuk mengetahui jenis dan manfaat yang diperoleh dalam pengelolaan pohon buah hutan. Metode analisis deskrirtif kualitif dengan wawancara kepada responden $0-10 \%$. Hasil yang didapat jenis buah durian (Durio zibethimus), kedondong (Spodias dulcis), kueni (Mangifera odorata), langsat (Lansium domesticum), melinjo (Gnentum gnemon), nangka (Arthocarpus interger), pisang (Musa Paradisiaca), rambutan (Nephelium lappaceum), sirsak (Annona muricata), sukun (Artocarpus communis), jambu air (Eugenia aquea). Pinang (Areca catechu), kelapa (Cocos mucifera), aren (Arenga pinnata), bamboo (Bambusa vulgaris), kopi (Coffea sp), kemiri (Aleurites moluccana). Manfaatnya sebagai pangan, pendapatan, obat, pewarna pakaian, bahan bangunan, dan bahan bakar. Pengelolaan pohon buah hutan di Lembo dengan melakukan kegiatan mengelola lahan antara lain (a) pemilihan lahan yaitu, dinilai masih sangat sederhana dengan melihat dari penampakan hutan, tajuknya hijau, sangat rapat dan lebat serta keadaan tanah yang berwarna gelap (b) penyiapan lahan yaitu, penebasan semak belukar, penebangan pohon, pencincangan batang atau ranting, pembakaran, dan sisa pembakaran dijadi abu sebagi pupuk tanah (c) pembibitan yaitu, bibit tidak dibeli melainkan didapat dari hutan atau permudan alam (d) penanaman yaitu, dilakukan dengan sengaja atau tidak sengaja (e) pemeliharaan yaitu, tidak ada pemeliharaan yang intensif (f) pemanenan yaitu, hasil pemanenan dinikmati setahun sekali (g) peremajaan yaitu, tanaman yang tidak produktif diganti.
\end{abstract}

Kata kunci: Jenis Pohon, Masyatakat, Manfaat, Pengelolaan

\section{ABSTRACT}

The Sambutan community manages a lot of Lembo (forest gardens) which is one of the traditional land uses which is generally dominated by vegetation and fruits. This study aims to determine the types and benefits obtained in the management of forest fruit trees. Qualitative descriptive analysis method by interviewing respondents $0-10 \%$. The results obtained were durian (Durio zibethimus), kedondong (Spodias dulcis), the kueni (Mangifera odorata), the langsat (Lansium domesticum), the melinjo (Gnentum gnemon), the jackfruit (Arthocarpus interger), the banana (Musa Paradisiaca), the rambut (Nephelium lappaceum), the soursop (Annona muricata), the breadfruit (Artocarpus communis), the guava (Artocarpus communis), the guava (Nephelium lappaceum), the soursop (Annona muricata) (Eugenia aquea). Areca nut (Areca catechu), coconut (Cocos mucifera), bamboo (Bambusa vulgaris), coffee (Coffea sp), candle nut (Arenga pinnata), coconut (Cocos mucifera), sugar palm (Arenga pinnata), coffee (Coffea sp), candlenut) (Aleurites moluccana). The benefits are food, revenue, medicine, dyeing of clothes, building materials, and fuel. Management of forest fruit trees in Lembo by conducting land management activities includes (a) selection of land, namely, it is still considered very simple by looking at the appearance of the forest, its green canopy, is very dense and dense, and the condition of the soil is dark (b) preparation of land, namely, shrub cutting, cutting trees, cutting stems or twigs, burning, and the rest of the burning is turned into ashes as soil fertilizer (c) nurseries, namely, seeds are not purchased but are obtained from the forest or natural regeneration (d) planting, that is, done intentionally or unintentionally (e) maintenance that is, there is no intensive maintenance $(f)$ harvesting, that is, the harvest is enjoyed once a year $(g)$ replanting, that is, replacing unproductive plants.

Keywords: Tree Types, Benefits, Community, Management 


\section{PENDAHULUAN}

Pemanfaatan tumbuh-tumbuhan hutan oleh masyarakat lokal merupakan pengetahuan yang sangat penting dalam mempertahankan kelangsungan hidup mereka (Appiah, Akoto, \& Tetteh, 2019). Bentuk pemanfaaan tumbuhan dalam kebutuhan sehari-hari sebagai bahan pangan, bahan sandang, bahan obat tradisional, rempah-rempah dan kosmetik serta perlengkapan dalam berbagai upacara tradisional memiliki corak yang berbeda dan khas di setiap daerah (Arabameri, Pradhan, \& Rezaei, 2019). Pemanfaatan tumbuhan di lembo atau kebun buah tradisional suku Dayak umumnya hanya sebatas buahbuahan saja, sehingga perlu penelitian guna memperoleh pengetahuan tentang manfaat lain yang dapat diperoleh dari limbo (Bui, Le, \& Hoang, 2018). Tujuan penelitian ini adalah untuk mengetahui pemanfaatan tumbuhan sebagai bahan obat tradisional yang digunakan oleh masyarakat Dayak Tunjung sekitar limbo (Chen, Zhang, Li, \& Shahabi, 2018). Melalui teknik pemanenan yang ramah lingkungan juga akan mengurangi kerusakan tegakan tinggal dan pengupasan tanah, sehingga tumbuhan obat yang bermanfaat untuk masyarakat masih banyak yang hidup di lantai hutan (Chiou, Tsai, \& Leung, 2010).

Tradisi pengobatan pada suatu kelompok masyarakat tidak terlepas dari kaitan budaya setempat, persepsi mengenai konsep sakit, sehat dan keragaman jenis tumbuhan obat (Deng, Shi, Jin, \& Wang, 2011). Cara pengolahan tumbuhan sebagai bahan obat pada setiap daerah di Indonesia memiliki cara yang khas dan diwariskan secara turun temurun, baik itu menggunakan berbagai jenis tumbuhan yang dipercaya dapat menyembuhkan, melalui perantara seorang dukun yang dipercaya memiliki kekuatan tertentu dalam dirinya sehingga dianggap mampu menyembuhkan penyakit atau melalui doa, upacara persembahan dan ritual serta mematuhi segala larangan agar mereka memperoleh keselamatan dan kesehatan dalam hidupnya (Domingosantos, Villarán, Rapp-arrarás, \& Provens, 2011). Dengan meningkatnya laju pertumbuhan penduduk dewasa ini, maka kebutuhan pangan, sandang dan papan pun semakin meningkat. Sebagian bahan-bahan yang diperlukan untuk memenuhi kebutuhan tersebut diperolah dari hutan (Feghhi, Teimouri, \& Makhdoum, 2017). Hutan sebagai sumber daya alam merupakan satu komponen dalam modal dasar Pembangunan Nasional (Fernandez, Delgado, Lopez-alonso, \& Manuel, 2018). Oleh karena itu diperlukan penyempurnaan dalam peningkatan pengelolaan sumber daya hutan agar dapat memberikan mafaat yang sebesar-besarnya bagi masyarakat (Grilli, Garegnani, Geri, \& Ciolli, 2017). Pengelolaan sumberdaya hutan pada dasar dilakukan melalui dua pola yaitu, pola pendekatan teknis dan pola pendekatan social budaya (loki et al., 2019). Hutan dan masyarakat disekitarnya mempunyai hubungan yang komplek dan terjalin dalam ekologis yang erat sekali dan tidak dapat terlpaskan, karena menyangkut kesejahteraan masyarakat (Irina, Javier, Teresa, Eurídice, \& María, 2019). Hubungan itu akan membentuk ekosistem. Hutan berperan penting terutama bagi masyarakat yang tinggal di dalam ataupun disekitar areal hutan (Jaziri, 2017). Masyarakat tersebut kehidupanya bias dikatakan lebih banyak bergantung dari hutan. Dapat dilihat pada kehidupan penduduk asli masyarakat Kalimntan Timur, masyarakatnya masih mengusahakan Lembo yang merupakan salah satu system pemanfaatn lahan secara tradisional yang terdiri dari berbagai jenis vegetasi yang bermanfaat yang umumnya didominsi oleh vegetasi jenis buah-buahan (Kašpar, Marušák, \& Vope, 2015).

Menurut undang-undang No. 41 tahun 1999 hutan didefinisikan sebagai suatu kesatuan ekosistem berupa hamparan lahan beisi sumber daya alam hayati yang didominasi pepohonan dalam persekutuan alam lingkungannya yang satu dengan yang lainnya tidak dapat dipisahkan (Korpilo, Virtanen, \& Saukkonen, 2018). Secara tradisional masyarakat yang bertempat tinggal di sekitar hutan atau dekat dengan hutan bergantung pada hutan yang menyediakan makanan, energy, tempat pemukiman dan segala macam hasil hutan yang digunakan sebagai hasil pendapatan baik untuk dijual maupun untuk digunakan sendiri dan dalam keadaan ditukar dengan sesama barang, "kebun hutan" merupakan bentuk khas dari lembo ladang yang terletak agak jauh dari areal pemukiman, dan umumnya terletak berada pada hutan sekunder bekas perladangan atau di dekat hutan primer 
(Liang, Li, Huang, Qin, \& Huang, 2017). Di samping berbagai jenis pohon buah-buahan, juga tumbuh berbagai jenis pohon maupun perdu yang bermanfaat bagi kehiduapan masyarakat setempat (Lin, Thomson, Hung, \& Lin, 2012). Komponen utama penyusun kebun hutan adalah pohon berkayu dari jenis buahbuahan yang berarti hasil utama dari kebun hutan adalah bahan pangan (buah) serta hasil lain yang dapat diproduksikan secara langsung antara lain bahan bangunan, bahan perkakas alat rumah tangga, kayu bakar, sayuran, dan lainnya.

Pengelolaan hutan pada hakekatnya adalah penggunaan cara-cara manajemen dan teknis kehutanan dalam menjalankan aktivitas terhadap suatu areal hutan (Mattheus \& Norton, 2013). Tujuaan dari pengelolaan hutan adalah untuk memanfaatkan hutan sesuai dengan fungsi-fungsi untuk mensejahterakan rakyat sekitar hutan khsusnya dan Indonesi umumnya (Mountains, Jin-chi, Jia-yao, Ji-shen, \& Hiroyuki, 2008).

\section{METODE PENELITIAN}

\section{Lokasi penelitian}

Penelitian dilaksanakan di Kelurahan Sambutan, Kecamatan Sambutan, Samarinda Kalimantan Timur, koordinat di antara 520000-530000 BT dan 99400009945000 LU. Luas lokasi penelitian $30 \mathrm{Km}^{2}$.

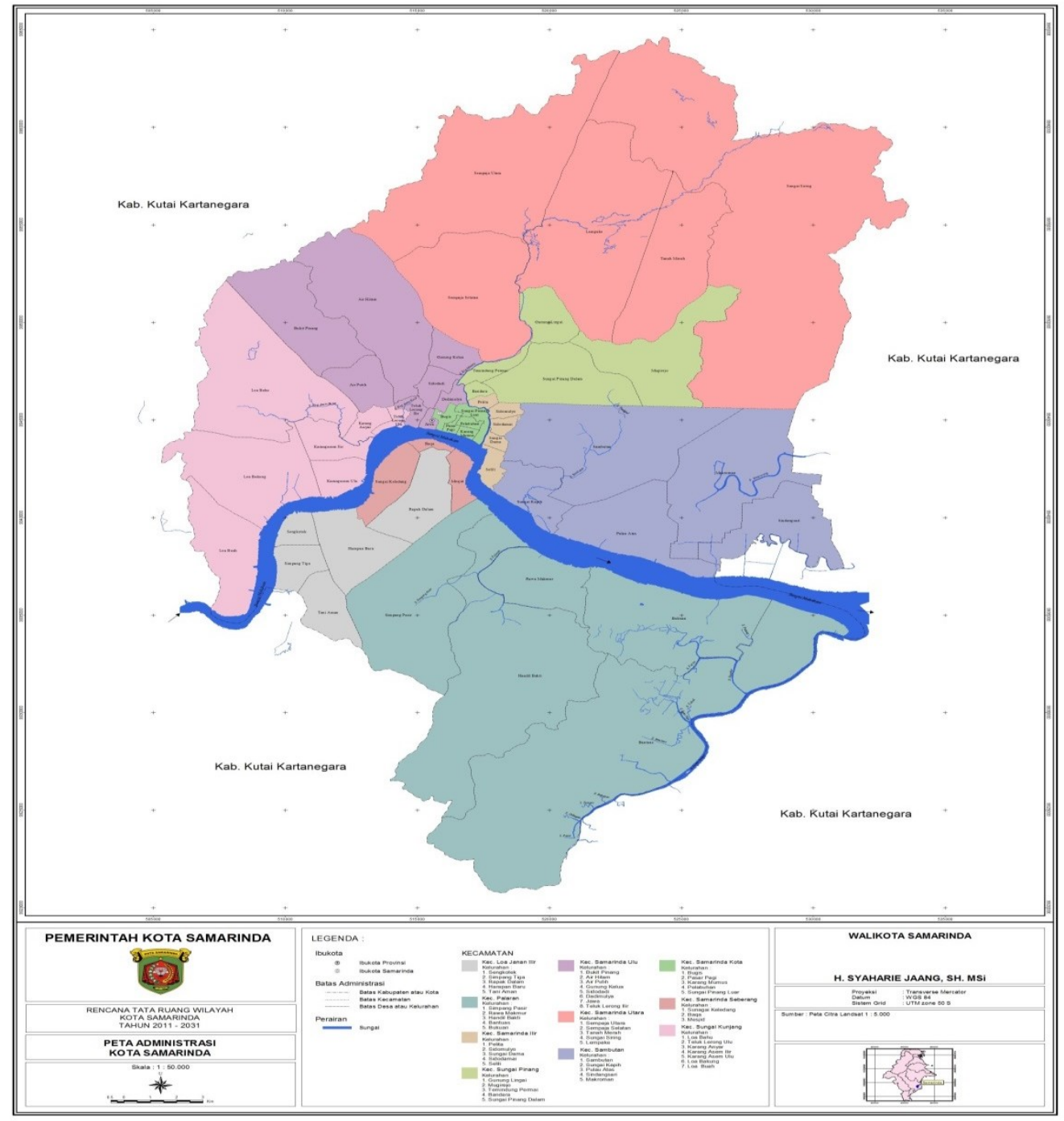

Gambar 1. Lokasi Penelitian Kelurahan Sambutan 


\section{Prosedur}

Pengambilan sampel menggunakan metode survey wawancara yang diambil secara purposive sampling/secara sengaja yang dipilih berdasarkan kriteria batasan 20 60 tahun dari responden sebanyak $10 \mathrm{KK}$. (Gambar 1.) analisis data dengan deskritif kualitatif dari jawaban dalam pertanyaan quisioner penelitian pada masyarakat.

\section{Analisis data}

Metode pengumpulan data paper dilakukan melalui observasi dan acuan buku, jurnal, serta penelitian terkait Pengelolan lembo (kebun hutan). Sebagian besar data mengenai didapatkan melalui laporan dan observasi langsung. Data yang digunakan meliputi jenis, manfaat serta pengelolaan pohon buah.

\section{Data Inventarisasi}

Data inventarisasi tumbuhan di lembo menggunakan metode garis berpetak, yaitu dengan cara membuat jalur rintisan kemudian pada rintisan tersebut dibuat plot dan subplot, untuk pembuatan plot dengan cara melompati satu plot dalam jalur sehingga sepanjang (tumbuhan dengan tinggi di atas $1.5 \mathrm{~m}$ dan diameter setinggi dada kurang dari $10 \mathrm{~cm}$ ) dan sub-plot dengan ukuran $1 \mathrm{~m}$ $\mathrm{x} 1 \mathrm{~m}$ untuk pengukuran tumbuhan tingkat semai (tumbuhan dengan tinggi di bawah $1.5 \mathrm{~m}$ ) dan tumbuhan bawah (Nandy, Kushwaha, \& Dadhwal, 2011). Banyak dan panjang jalur disesuaikan dengan luas Lembo yang akan diinventarisasi, untuk jumlah plot dan sub plot pada dua lokasi Lembo masing-masing adalah 105 plot, jumah ini diharapkan dapat mewakili keadaan lembo secara umum. Data yang diperoleh kemudian diidentifikasi untuk mengetahui nama lokal dan nama ilmiahnya. Menurut Indriyanto (2015) dan Ardana (2012), metode garis berpetak adalah modifikasi dari metode petak ganda dan metode jalur, yaitu dengan cara membuat jalur rintisan kemudian pada rintisan tersebut dibuat petak, untuk pembuatan petak dengan cara melompati satu petak dalam jalur sehingga sepanjang garis rintis terdapat petak-petak pada jarak tertentu yang sama, bentuk dan ukuran petak-petak pengamatan serta peletakannya pada setiap garis rintis dapat dilihat pada Gambar 1.

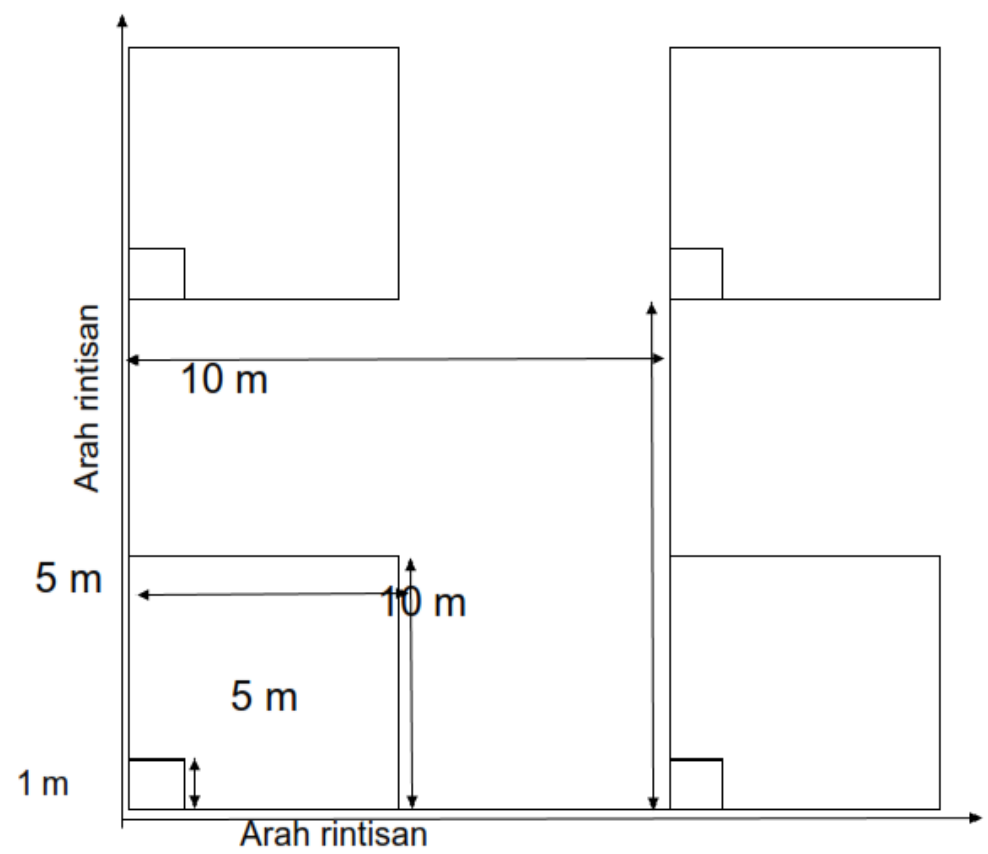

Gambar 2. Bentuk dan penempatan plot dan sub-plot pengamatan pada setiap jalur pengamatan

(Narulita, Fitriany, Zain, \& Budi, 2016). 


\section{Data pemanfaatan tumbuhan}

Data pemanfaatan tumbuhan yang ditemukan di lembo dilakukan melalui pendekatan emik (metode pendekatan dari sudut pandang suatu kelompok etnis itu sendiri, etik metode pendekatan dari sudut pandang peneliti) dengan cara mewawancarai responden yang dipilih dengan pengumpulan data dilakukan dengan wawancara secara semi-terstruktur dan menemui responden secara langsung (Ngoc-thach et al., 2018). Dalam penelitian ini diambil secara sensus dikarenakan dalam 2 lokasi penelitian tersebut hanya ditemukan 15 orang yang memahami tentang pemanfaatan tumbuhan sebagai bahan obat tradisional (Nino, Mamo, Mengesha, \& Sahle,
2017). Data inventarisasi yang diperoleh kemudian dihitung kerapatan per hektarnya menggunakan rumus kerapatan (Panagoda \& Weerasinghe, 2019).

$\begin{aligned} & \text { Kerapatan } \\ & \text { per hektar }\end{aligned}=\frac{10.000}{\text { luas plot contoh }} \times$ jumlah individu

\section{HASIL DAN PEMBAHASAN}

Berbagai jenis vegetasi buah-buahan terdapat di lembo. Sebagaian besar jenis buah-buahan tersebut banyak dijumpai di dalam hutan sekunder, disajikan pada tabel 1 berikut

Tabel 1. Komposisi Jenis serta Manfaat buah-buahan yang terdapat di Lembo

\begin{tabular}{|c|c|c|c|}
\hline No. & Nama Daerah & Nama Jenis & Manfaat \\
\hline 1 & Durian & Durio zibethimus & $\begin{array}{l}\text { Buah (pangan, pendapatan) } \\
\text { Kayu (peralatan, bahan bangunan) } \\
\text { Kulit buah (obat nyamuk) } \\
\text { Daunnya (obat melahirkan) }\end{array}$ \\
\hline 2 & Kedondong & Spodias dulcis & Buah (pangan), Daun (sayuran) \\
\hline 3 & Kueni & Mangifera odorata & Buah (pangan, pendapatan) \\
\hline 4 & Langsat & Lansium domesticum & $\begin{array}{l}\text { Buah (pangan, pendapatan) } \\
\text { Kulit batang (obat sakit perut) } \\
\text { Kayu (bahan bakar) }\end{array}$ \\
\hline 5 & Melinjo & Gnentum gnemon & Buah dan daun (pangan, pendapatan) \\
\hline 6 & Nangka & Arthocarpus interger & $\begin{array}{l}\text { Buah (pangan, pendapatan) } \\
\text { Kayu (bahan bangunan) } \\
\text { Kulit (bahan pewarna pakaian) }\end{array}$ \\
\hline 7 & Pisang & Musa Paradisiaca & $\begin{array}{l}\text { Buah (pangan, pendapatan) } \\
\text { Tunas muda (sayuran) }\end{array}$ \\
\hline 8 & Rambutan & Nephelium lappaceum & $\begin{array}{l}\text { Buah (pangan, pendapatan) } \\
\text { Biji (minyak untuk bahan campuran } \\
\text { pembuatan lilin dan sabun) } \\
\text { Air rebusan akar (obat) } \\
\text { Pucuk daun (pewarna kain) }\end{array}$ \\
\hline 9 & Sirsak & Annona muricata & $\begin{array}{l}\text { Buah (pangan), Tunas (obat deman) } \\
\text { Daun (obat hama) }\end{array}$ \\
\hline 10 & Sukun & Artocarpus communis & Buah (pangan, pendapatan) \\
\hline 11 & Jambu air & Eugenia aquea & Buah (pangan) \\
\hline 12 & Pinang & Areca catechu & Buah (obat, pendapatan) \\
\hline 13 & Kelapa & Cocos mucifera & $\begin{array}{l}\text { Buah (pangan, pendapatan) } \\
\text { Daun (ketupat, sapu lidi, janur) } \\
\text { Batang (kayu bakar) }\end{array}$ \\
\hline 14 & Aren & Arenga pinnata & $\begin{array}{l}\text { Buah (pangan, pendapatan) } \\
\text { Daun (sapu lidi) }\end{array}$ \\
\hline 15 & Bambu & Bambusa vulgaris & $\begin{array}{l}\text { Buah (pangan, pendapatan) } \\
\text { Batang (dinding rumah) }\end{array}$ \\
\hline 16 & Kopi & Coffea $s p$ & Buah (pangan, pendapatan) \\
\hline 17 & Kemiri & Aleurites moluccana & Buah (pangan, pendapatan) \\
\hline
\end{tabular}


Jenis buah-buah tersebut memberikan manfaat yang sangat besar sekali kepada masyarakat di desa, jika hasil pananennya melimpah sehingga dapat dijual. Dari hasil penelitian menunjukkkan beberapa jenis buah dapat diperdagangkan, karena hasil buah-buahan tersebut sangat berlebihan. Jadi selain untuk dikonsumsi sendiri juga dapat dijual, adalah jenis buah durian (Durio zibethimus), kedondong (Spodias dulcis), kueni (Mangifera odorata), langsat (Lansium domesticum), melinjo (Gnentum gnemon), nangka (Arthocarpus interger), pisang (Musa Paradisiaca), rambutan (Nephelium lappaceum), sirsak (Annona muricata), sukun (Artocarpus communis), jambu air (Eugenia aquea). Pinang (Areca catechu), kelapa (Cocos mucifera), aren (Arenga pinnata), bamboo (Bambusa vulgaris), kopi (Coffea $s p)$, kemiri (Aleurites moluccana). Berbagai jenis tanaman yang ada di areal lembo sangat banyak manfaatnya, baik berupa bahan pangan, bahan bangunan, maupun pendapatan tunai. Selain manfaat yang didapat diberikan dari tanaman buah tersebut adapula beberapa manfaat yang diberikan dari tanaman selain buah yang tumbuh di areal lembo.

\section{Sistem Pengelolaan}

Sebagaimana telah diketahui bahwa perkembangan lembo erat kaitannya dengan kegiatan perladangan, oleh karenanya tahapan perladangan juga merupakan bagian dari sistem pengelolaan jenis buah-buahan hutan.

\section{a. Pemilihan lahan}

Lahan yang digunakan sebagai tempat berladang dengan cara pemilihan lahan dinilai masih sangat sederhana sekali yaitu mereka melihat dari penampakan hutan, tajuknya terlihat hijau dan sangat rimbun banyaknya vegetasi yang tumbuhan di lahan tersebut serta keadaan tanah yang berwarna gelap. Dengan melihat ketiga kriteria tersebut, maka masyarakat yakin kalau lahan tersebut sangat cocok untuk dibuat ladang, berarti lahan tersebut subur.

\section{b. Penyiapan lahan}

Hutan tersebut sebelum dijadikan ladang, masyarakat melakukan beberapa kegiatan awal untuk pembuatan arela ladang. Kegiatan tersebut:
- Penebasan terhadap semak belukar dan tumbuhan bawah, kecuali jenis komersial. Kegiatan penebasan dilakukan oleh lakilaki maupun perempuan dan remaja.

- Penebangan pohon yang berdiameter yang besar dilakukan oleh pekerja lakilaki.

- Pencincangan batang atau ranting untuk memudahkan pembakaran dilakukan oleh pekerja perempun dan laki-laki. Kayu yang dapat digunakan diambil, baik nantinya digunakan untuk membuat pondok atau dikeringkan untuk dijadikan kayu bakar. Hasil penebasan dan pencincangan dibiarkan beberapa hari agar mongering, selanjutnya ditumpuk ditempat yang agak dari tegakan di lahan sekitarnya.

- Pembakaran dilakukan setelah sebelumnya membuat sekat bakar agar api tidak menjalar kemana-mana. Biasanya pembakaran diulangi lagi beberapa hari kemudian atau sekitar satu minggu, yang maksudnya untuk membersihkan sisa-sisa pembakaran.

- Sisa-sisa pembakaran yang belum habis pada pembakaran pertama, dan menghasilkan pembakaran sempurna pada pembakaran ke dua yaitu abu. Lahan yang sudah bersih tersebut mereka buat ladang dengan ditanami padi dan sayuran. Penaman di ladang tersebut dilakukan oleh pekerja laki-laki dan perempuan baik dewasa maupun remaja, luas ladang penduduk rata-rata 0,5 ha.

\section{c. Pembibitan}

Ladang yang dinilai sudah tidak produktif lagi, setelah diketahui kesuburan tanah mulai berkurang yang ditandai dengan rendahnya hasil tanaman, maka masyarakat mulai membuka lahan baru. Sebelum lahan tersebut ditinggalkan (bera) terlebih dahulu ditanami dengan jenis tanaman tahunan yang bermanfaat, dan kebanyakan menanam jenis buah-buahan. Bibit tanaman buah tidak dibeli, tapi dapat dari hutan, ada juga didapat dari pemberian orang, tukar-menukar dengan tetangga atau dari permudaan alam yang tumbuh dari biji yang dibuang oleh pemilik lahan pada saat berladang atau oleh orang yang lewat sambil memakan jenis buah tersebut. 


\section{d. Penanaman}

Dalam penanaman ada yang masyarakat lakukan dengan sengaja dan ada juga dengan tidak sengaja. Penanaman mereka lakukan dengan sengaja hanya pada awal pembentukan lembo, untuk selanjutnya tanaman yang ada merupakan hasil anakan alami dan juga dari buangan biji-biji buah dari orang yang makan di area tersebut ataupun melintasi areal lembo yang kemudian tumbuh menjadi tanaman. Peralatan yang mereka gunakan untuk menanam berupa cangkul, tugal, parang, mandau, dan tenaga kerja lakilaki dan perempuan dewasa dan juga anakanak.

Lembo yang ada sekarang diantaranya merupakan warisan dari nenek mereka yang juga merupakan masyarakat peladang, saat ini untuk membuat lembo sendiri (baru) sudah sulit, karena masyarakat desa hidupnya sudah menetap. Selain itu juga karena semakin sempitnya lahan yang ada akibat sebagian besar sudah ada pemiliknya. Dalam melakukan penaman, mayarakat bersama-sama anggota keluarga dan umumnya tidak menggunakan tenaga upahan.

\section{e. Pemeliharaan}

Pada dasarnya tidak ada pemeliharaan yang intensif pada lembo sebagaimana yang dijumpai pada perkebunan-perkebunan tanaman keras (kelapa sawit dan karet). Pemeliharaan lembo yang letaknya masih disekitar perladangan atau dikenal dengan lembo ladang tidak rutin. Biasanya setelah dilakukan penanaman, mereka hanya melakukan pemelihaaraan satu sampai tiga kali setahun saja. Setelah pohon tumbuh dengan baik, mereka membiarkannya beradaptasi dan berkompetisi dengan lingkungannya sampai pohon tersebut mulai menghasilkan.

\section{f. Pemanenan}

Jenis-jenis tanaman buah yang ada di lembo dapat memberikan hasil berupa buah jika musimnya tiba dan buah-buah tersebut dapat dinikmati hasilnya setahun sekali. Dalam kegiatan pemanenan hasil buah, masyarakat ada yang memanennya bersama anggota keluarga mereka dan ada juga menggunakan orang suruhan.

\section{g. Peremajaan}

Tanaman-tanaman pada area lembo yang tidak produktif diganti. Bibitnya diperoleh disekitar lembo itu sendiri, dari hutan-hutan disekitar atau dari daerah lain. Pada masa sekarang untuk perluasan area lembo adalah tidak mungkin dilakukan, karena dengan semakin bertambahnya pengguna lahan sehingga menambah sempitnya lahan-lahan kosong di luar area lembo.

Lembo merupakan kumpulan berbagai jenis vegetasi yang tumbuh tidak teratur, terutama didominasi oleh vegetasi buahbuahan. Lembo banyak dijumpai pada lahan yang dimiliki oleh masyarakat setempat. Istilah lembo yaitu suatu sistem pemanfaatan lahan secara tradisional, yang dilakukan oleh masyarakat setempat pada bekas area ladang yang diberakan atau ditinggalkan dalam beberapa waktu.

\section{KESIMPULAN DAN SARAN}

Keberadaan budidaya Lembo yang dikelola oleh masyarakat Sambutan didominasi oleh jenis buah-buahan diantaranya durian (Durio zibethimus), kedondong (Spodias dulcis), kueni (Mangifera odorata), langsat (Lansium domesticum), melinjo (Gnentum gnemon), nangka (Arthocarpus interger), pisang (Musa Paradisiaca), rambutan (Nephelium lappaceum), sirsak (Annona muricata), sukun (Artocarpus communis), jambu air (Eugenia aquea). Pinang (Areca catechu), kelapa (Cocos mucifera), aren (Arenga pinnata), bamboo (Bambusa vulgaris), kopi (Coffea $s p)$, kemiri (Aleurites moluccana). Hasil penelitian menunjukkkan beberapa jenis buah dapat dikonsumsi sendiri dan diperdagangkan.

Diperlukan perawatan yang intensif baik sekarang maupun yang akan datang, agar hasil budidaya Lembo yang sudah ada dapat ditingkatkan kualitasnya. Dalam pemanfaatan lahan secara tradisional perlu dipertahankan baik dalam pengelolaan, kuantitas dan kualitas.

\section{DAFTAR PUSTAKA}

Appiah, A., Akoto, D., \& Tetteh, S. (2019). The Egyptian Journal of Remote Sensing and Space Sciences Assessment of vegetation dynamics using remote sensing and GIS : A case of Bosomtwe Range Forest Reserve, 
Ghana. The Egyptian Journal of Remote Sensing and Space Sciences, 22(2), 145-154. https://doi.org/10.1016/j.ejrs.2018.04.00 4

Arabameri, A., Pradhan, B., \& Rezaei, K. (2019). Gully erosion zonation mapping using integrated geographically weighted regression with certainty factor and random forest models in GIS. Journal of Environmental Management, 232(November 2018), 928-942. https://doi.org/10.1016/j.jenvman.2018. 11.110

Bui, D. T., Le, V. H., \& Hoang, N. (2018). AC US CR. Ecological Informatics, \#pagerange\#.

https://doi.org/10.1016/j.ecoinf.2018.08. 008

Chen, W., Zhang, S., Li, R., \& Shahabi, H. (2018). Science of the Total Environment Performance evaluation of the GIS-based data mining techniques of best- fi rst decision tree, random forest, and naïve Bayes tree for landslide susceptibility modeling. Science of the Total Environment, 644, 1006-1018.

https://doi.org/10.1016/j.scitotenv.2018. 06.389

Chiou, C., Tsai, W., \& Leung, Y. (2010). Landscape and Urban Planning A GISdynamic segmentation approach to planning travel routes on forest trail networks in Central Taiwan. Landscape and Urban Planning, 97(4), 221-228. https://doi.org/10.1016/j.landurbplan.20 10.06.004

Deng, S., Shi, Y., Jin, Y., \& Wang, L. (2011). A GIS-based approach for quantifying and mapping carbon sink and stock values of forest ecosystem: A case study, 5, 1535-1545. https://doi.org/10.1016/j.egypro.2011.03 .263

Domingo-santos, J. M., Villarán, R. F. De, Rapp-arrarás, Í., \& Provens, E. C. De. (2011). Landscape and Urban Planning The visual exposure in forest and rural landscapes: An algorithm and a GIS tool. Landscape and Urban Planning, 101(1), 52-58 https://doi.org/10.1016/j.landurbplan.20 10.11.018

Feghhi, A. J., Teimouri, S., \& Makhdoum, M.
F. (2017). The Assessment of Degradation to Sustainability in an Urban Forest Ecosystem by GIS. Urban Forestry \& Urban Greening. https://doi.org/10.1016/j.ufug.2017.06.0 09

Fernandez, P., Delgado, E., Lopez-alonso, M., \& Manuel, J. (2018). Science of the Total Environment GIS environmental information analysis of the Darro River basin as the key for the management and hydrological forest restoration. Science of the Total Environment, 613614, 1154-1164. https://doi.org/10.1016/j.scitotenv.2017. 09.190

Grilli, G., Garegnani, G., Geri, F., \& Ciolli, M. (2017). Cost-benefit Analysis with GIS : An Open Source Module for the Forest Bioenergy Sector. Energy Procedia, 107(September 2016), 175-179. https://doi.org/10.1016/j.egypro.2016.12 .164

loki, K., Mohd, N., Ludwig, R., James, D., Wah, S., Azwan, S., ... Phua, M. (2019). Supporting forest conservation through community-based land use planning and participatory GIS lessons from Crocker Range Park , Malaysian Borneo. Journal for Nature Conservation, 52(September), 125740. https://doi.org/10.1016/j.jnc.2019.12574 0

Irina, L., Javier, B., Teresa, C. M., Eurídice, L., \& María, C. L. (2019). Land Use Policy Integrating ecological and socioeconomic criteria in a GIS-based multicriteria-multiobjective analysis to develop sustainable harvesting strategies for Mexican oregano Lippia graveolens Kunth, a non-timber forest product. Land Use Policy, 81(March 2018), 668-679. https://doi.org/10.1016/j.landusepol.201 8.11 .038

Jaziri, W. (2017). Using GIS and multicriteria decision aid to optimize the direction of trees cutting in the forest ecosystem: A case study. Computers and Electronics in Agriculture, 143(October), 177-184. https://doi.org/10.1016/j.compag.2017.1 0.013

Kašpar, J., Marušák, R., \& Vope, P. (2015). Application note GIS tool for optimization of forest harvest- 
scheduling, $\quad 113, \quad 254-259$. https://doi.org/10.1016/j.compag.2015.0 3.001

Korpilo, S., Virtanen, T., \& Saukkonen, T. (2018). More than A to B: Understanding and managing visitor spatial behaviour in urban forests using public participation GIS, 207, 124-133. https://doi.org/10.1016/j.jenvman.2017. 11.020

Liang, L., Li, X., Huang, Y., Qin, Y., \& Huang, $H$. (2017). Integrating remote sensing, GIS and dynamic models for landscapelevel simulation of forest insect disturbance. Ecological Modelling, 354, 1-10.

https://doi.org/10.1016/j.ecolmodel.2017 .03 .007

Lin, C., Thomson, G., Hung, S., \& Lin, Y. (2012). A GIS-based protocol for the simulation and evaluation of realistic 3$D$ thinning scenarios in recreational forest management. Journal of Environmental Management, 113, 440446.

https://doi.org/10.1016/j.jenvman.2012. 09.001

Mattheus, C. R., \& Norton, M. S. (2013). Anthropocene Comparison of pondsedimentation data with a GIS-based USLE model of sediment yield for a small forested urban watershed. Biochemical Pharmacology, 2, 89-101. https://doi.org/10.1016/j.ancene.2013.1 0.003

Mountains, D., Jin-chi, Z., Jia-yao, Z., Jishen, S., \& Hiroyuki, N. (2008). Development of GIS-based FUSLE model in a Chinese fir forest subcatchment with a focus on the litter in the, 255, 2782-2789. https://doi.org/10.1016/j.foreco.2008.01. 045

Nandy, S., Kushwaha, S. P. S., \& Dadhwal, V. K. (2011). Forest degradation assessment in the upper catchment of the river Tons using remote sensing and GIS. Ecological Indicators, 11(2), 509-513.

https://doi.org/10.1016/j.ecolind.2010.07 .006

Narulita, S., Fitriany, A., Zain, M., \& Budi, L. (2016). Geographic Information System ( GIS ) application on urban forest development in Bandung City, 33, 279-
289.

https://doi.org/10.1016/j.proenv.2016.03 .079

Ngoc-thach, N., Ngo, D. B., Xuan-canh, P., Hong-thi, N., Thi, B. H., Nhatduc, H., \& Dieu, T. B. (2018). US CR. Ecological Informatics, \#pagerange\#. https://doi.org/10.1016/j.ecoinf.2018.05. 009

Nino, K., Mamo, Y., Mengesha, G., \& Sahle, K. (2017). GIS based ecotourism potential assessment in Munessa Shashemene Concession Forest and its surrounding area, Ethiopia. Applied Geography, 82, 48-58. https://doi.org/10.1016/j.apgeog.2017.0 2.010

Panagoda, P. A. B. G., \& Weerasinghe, V. P. A. (2019). Acta Ecologica Sinica A potential habitat corridor for Western Purple-faced Langur between Forest Reserves in Sri Lanka: GIS as a tool in connectivity modelling. Acta Ecologica Sinica, 39(3), 194-201. https://doi.org/10.1016/j.chnaes.2018.1 2.007 